\title{
Information-analytical system of chemical technology processes modeling by the use of parallel calculations
}

\author{
I V Akhmetov ${ }^{1}$ and I M Gubaydullin ${ }^{1,2}$ \\ ${ }^{1}$ Ufa State Petroleum Technological University, Kosmonavtov St. 1, Ufa, Russia, 450062 \\ ${ }^{2}$ Institute of Petrochemistry and Catalysis of the Russian Academy of Sciences, Prospekt \\ Oktyabrya 141, Ufa, Russia, 450075
}

\begin{abstract}
An information-analytical system for modelling of chemical technology processes by the use of parallel computing has been developed. On the basis of this system a kinetic model for the synthesis of benzylidene benzylamine has been built. The optimal conditions to maximum yield of target product were found.
\end{abstract}

\section{Introduction}

In order to explore mechanisms for chemical technology processes, the kinetic models should be developed. The development of a kinetic model requires solving the inverse kinetic task. This stage the most laborious and time consuming [1-4]. The use of parallel computing is becoming increasingly instrumental method of mathematical processing of experimental data [5, 6].

Inverse chemical kinetics problems suppose a significant amount of computation. The use of highperformance computing systems has fundamentally changed the ability to analyze complex chemical processes. A detailed analysis of rather complex kinetic models with a large amount of experimental information became available. The time required to build kinetic models has been significantly reduced. The accuracy of solutions has been improved.

Authors of this work has developed and tested the information-analytical system for modeling chemical technology processes. On the basis of the technology of parallel calculations the actual method of search of kinetic parameters is offered.

The use of high-performance systems allows us to reduce the time of study and development of new chemical processes.

\section{Information-analytical system for modelling chemical technology processes}

The information-analytical system (IAS) is proposed to use for studying chemical technology processes. Its structure is given on the figure 1 .

Input information flows include:

- Experimental conditions: reactor type, process flow mode, temperature, pressure, volume of reaction mixture.

- Chemical formula involved in the reaction.

- Concentrations at the initial time.

- Concentrations at some fixed points in time. 
- Evaluation of kinetic parameters: ratios between constants, certainty intervals of some kinetic parameters.

- Proposed mechanisms of chemical reactions.

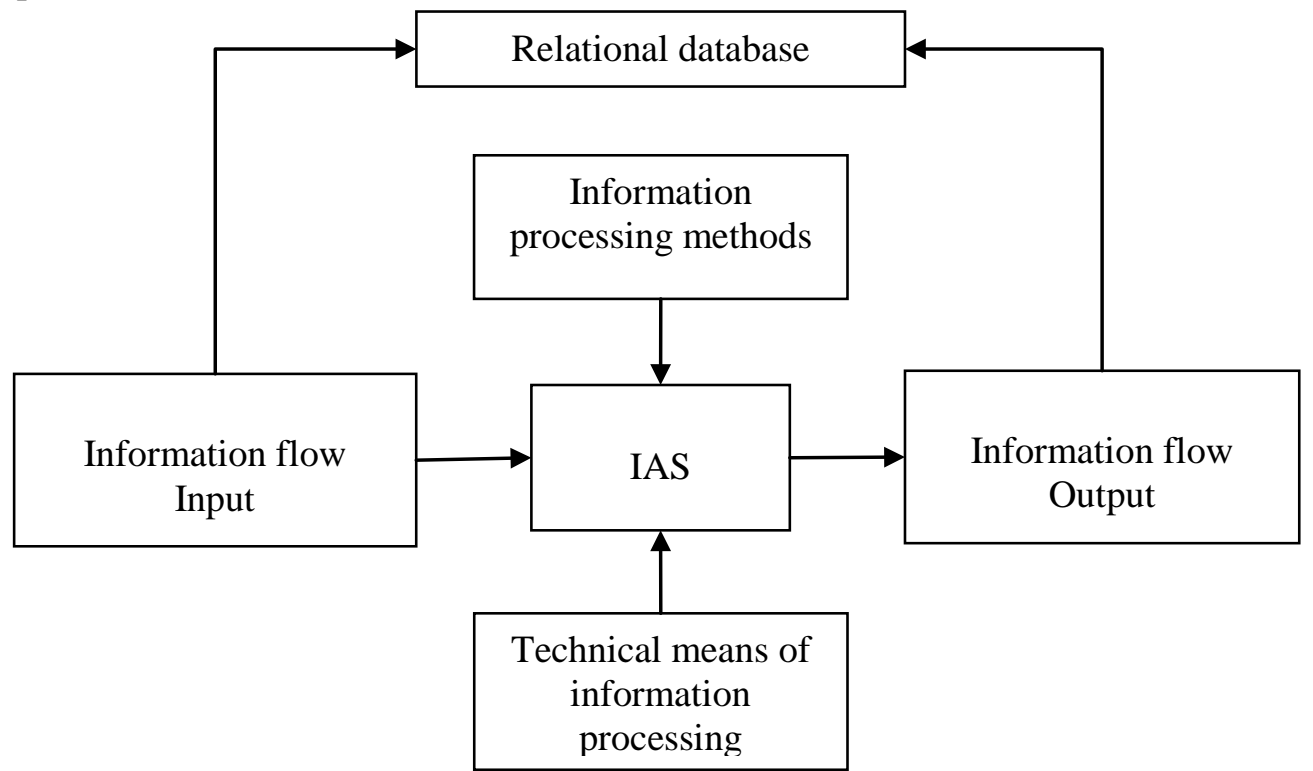

Figure 1. Information-analytical system structure for modeling chemical technology processes.

Information processing methods include:

- The algorithm for solving the direct kinetic problem.

- Parameters of computing control in solving the inverse kinetic problem.

- The algorithm for solving the inverse problem.

- Graph plotting for comparison the calculated and experimental concentrations of the reacting substances.

- The algorithm for determining the activation energies of the reaction stages.

Output information flows include:

- Calculated concentrations of all reacting substances.

- Calculated activation energies of all reaction stages.

- Graphs for comparison the calculated and experimental concentrations of the reacting substances.

- Graphs of change in reaction stage rate.

Technical means of information processing include:

- Experimental unit.

- Industrial reactor.

- Computing system: personal computer, multiprocessor computer system.

\section{Application of parallel computing}

The genetic algorithm for the parallel solution of the inverse problem of chemical kinetics is the most effective. This algorithm is borrowed from biology. It is based on the idea of selection, i.e. the predominant reproduction of the most adapted individuals [7]. The practical application of the genetic algorithm in all known cases has led to positive results [8,9]. The genetic algorithm is a universal method for finding the optimum regardless of the complexity of the functions [9]. The basis of the genetic algorithm presents the following sequence of operations.

On the first step the algorithm randomly creates the initial population of $\mathrm{N}$ individuals. Then $\mathrm{N}$ points are formed in the space of kinetic parameters. Each point has $\mathrm{m}$ coordinates, i.e. values of the parameters. 
At the stage of mutation, individuals of the population change in accordance with a predetermined operation. The coordinates/parabolic descent from the points of the space were taken as the operation of mutation.

At the stage of selection, a certain fraction of the entire population is selected. The chosen fraction will remain "alive" at this stage of evolution. The probability of survival of the individual depends on the value of the adaptiveness function for this individual. The function of adaptiveness is characterized by the residual function. The fraction of survivors (s) is a parameter of the genetic algorithm. According to the results of the selection from $\mathrm{N}$ individuals of the population the total population will comprise $s \times N$ individuals. In the considered case $s=1 / 2$. The crossing is used to form a new generation. It needs two parents to produce a descendant. To form a new point in the parameter space, one of the "survivors" and one of the "dying" points are selected as parents. The crossing is carried out by choosing $\mathrm{m} / 2$ coordinates from the first point and the remaining ones from the second. In this case, the descendant inherits features of both parents. To exclude the degradation of the population, the individuals for reproduction are selected from the entire population. This set of actions is repeated iteratively. By this way the "evolutionary process" is modeled and several life cycles (generations) continue. The algorithm stops when one of the following conditions is met:

- finding a global or suboptimal solution;

- exhaustion of the number of generations for evolution;

- exhaustion of time given for evolution.

Parallelization of the computational process takes place at the stage of initial filling. Pseudorandom points in the parameter space are uniformly distributed over the flows of a multi-core computing system. The mutation is carried out by each flow independently. Data exchange is carried out at the selection stage. The autonomous operation time of flows significantly exceeds the interaction time between flows. Therefore this algorithm is effective.

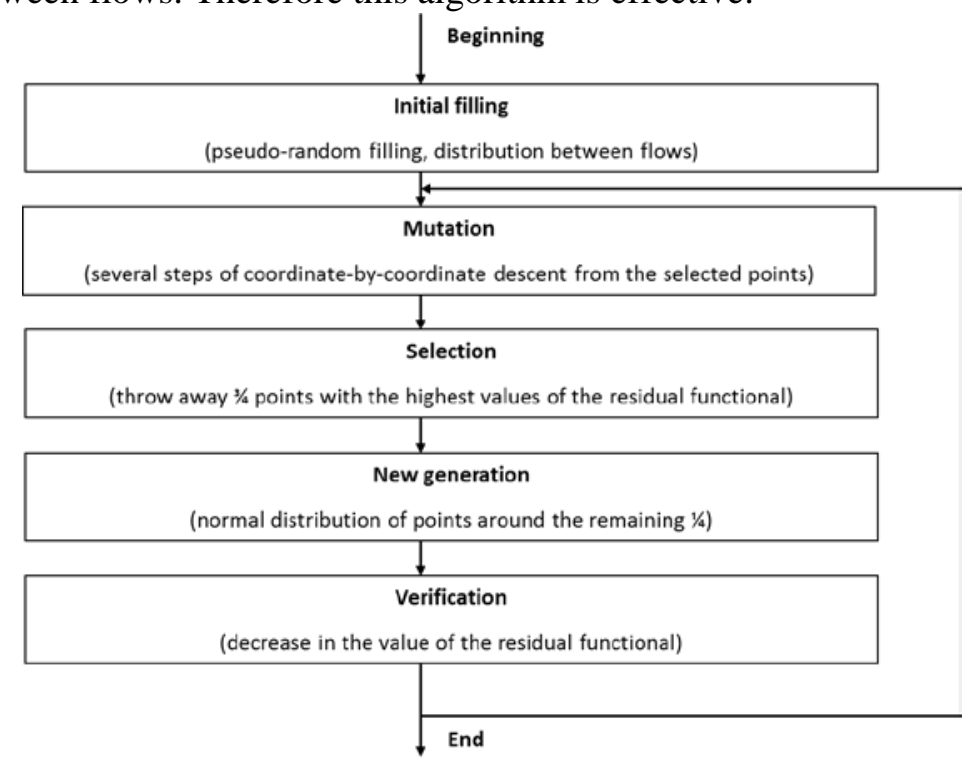

Figure 2. Genetic algorithm.

\section{Kinetic model of the reaction for the synthesis of benzylidene benzylamine}

The developed information-analytical system was tested when modeling of a kinetic model for the synthesis of benzylidene benzylamine. In the series of Schiff bases, N-benzylidene benzylamine has an important place and has wide application in practice. In particular, N-benzylidene benzylamine is known as an indicator for the quantitative determination of lithium-organic compounds by titrimetric method [10-12]. N-benzylidene benzylamine is used as an initial compound for the synthesis of a number of heterocycles. It has a wide range of physiological activity: analgesic, anticonvulsive, anticonvulsant [13]. Based on the analysis of the experimental data and the results of their 
mathematical treatment [14-15] the following sequence of chemical transformations in reactions of benzylideneaniline synthesis is proposed:

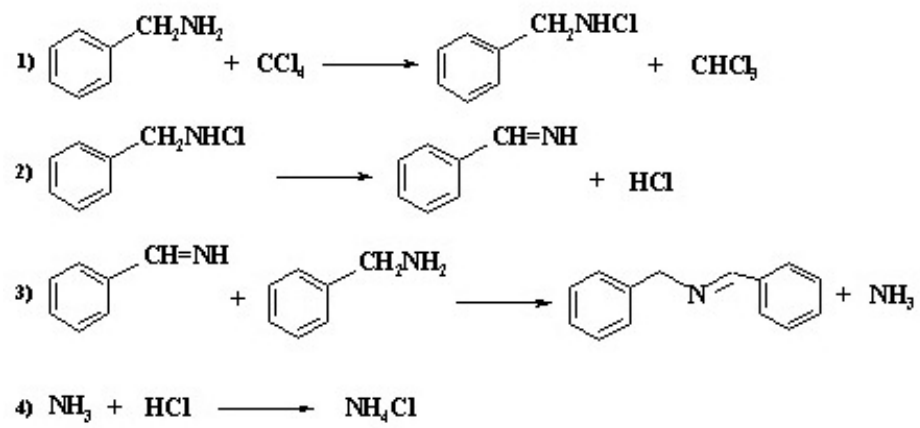

The sequence of reaction transformations and their corresponding kinetic equations are represented by equations:

1. $\mathrm{C}_{1}+\mathrm{C}_{2} \rightarrow \mathrm{C}_{3}+\mathrm{C}_{4}$

$$
\begin{aligned}
& \mathrm{W}_{1}=\mathrm{k}_{1} \mathrm{C}_{1} \mathrm{C}_{2} \\
& \mathrm{~W}_{2}=\mathrm{k}_{2} \mathrm{C}_{3} \\
& \mathrm{~W}_{3}=\mathrm{k}_{3} \mathrm{C}_{5} \mathrm{C}_{1} \\
& \mathrm{~W}_{4}=\mathrm{k}_{4} \mathrm{C}_{8} \mathrm{C}_{6}
\end{aligned}
$$

2. $\mathrm{C}_{3} \rightarrow \mathrm{C}_{5}+\mathrm{C}_{6}$

3. $\mathrm{C}_{5}+\mathrm{C}_{1} \rightarrow \mathrm{C}_{7}+\mathrm{C}_{8}$

4. $\mathrm{C}_{8}+\mathrm{C}_{6} \rightarrow \mathrm{C}_{9}$

where $\mathrm{C}_{\mathrm{i}}$ - concentration of components, mol/L: $\mathrm{C}_{1}=\mathrm{C}_{7} \mathrm{H}_{9} \mathrm{~N}$ - benzylamine, $\mathrm{C}_{2}=\mathrm{CCl}_{4}-$ carbon tetrachloride, $\mathrm{C}_{3}=\mathrm{C}_{7} \mathrm{H}_{8} \mathrm{NCl}$ - chlorbenzylamine, $\mathrm{C}_{4}=\mathrm{CHCl}_{3}-$ chloroform, $\mathrm{C}_{5}=\mathrm{C}_{7} \mathrm{H}_{7} \mathrm{~N}-1$ phenylmethanimine, $\mathrm{C}_{6}=\mathrm{HCl}$ - hydrogen chloride, $\mathrm{C}_{7}=\mathrm{C}_{14} \mathrm{H}_{13} \mathrm{~N}$ - benzylidene benzylamine, $\mathrm{C}_{8}=\mathrm{NH}_{3}-$ ammonia, $\mathrm{C}_{9}=\mathrm{NH}_{4} \mathrm{Cl}$ - ammonium chloride; $\mathrm{W}_{\mathrm{j}}$ - rate of the $\mathrm{j}$-th reaction, mol/(L×h); $\mathrm{k}_{\mathrm{j}}$ - kinetic rate constant of the $\mathrm{j}$-th reaction, $\mathrm{l} \times \mathrm{mol}^{-1} \times \mathrm{h}^{-1}(\mathrm{j}=1,3,4), \mathrm{h}^{-1}$.

The kinetic equations of the transformation sequence are analyzed within the law of acting masses [16]. The correct description of a laboratory reactor with a stirrer is the ideal mixing model:

$$
\begin{gathered}
\frac{d \bar{N}}{d t}=F_{N}, F_{N}=\frac{1}{V_{o}} \sum_{j=1}^{J} \delta_{j} \omega_{j}, \delta_{j}=\sum_{i=1}^{I} v_{i j} \\
\frac{d X_{i}}{d t}=\frac{F_{i}-X_{i} F_{N}}{\bar{N}}
\end{gathered}
$$

with the initial conditions: at $t=0, X_{i}=X_{i}^{o}, \bar{N}=1$, где $\overline{\mathrm{N}}=\mathrm{C} / \mathrm{C}_{0}-$ the relative change in the number of moles of the reaction mixture; $C$ and $C_{o}-$ molar density and its initial value, mol $/ \mathrm{L}$; $\mathrm{X}_{\mathrm{i}}=\mathrm{C}_{\mathrm{i}} / \mathrm{C}$ - concentration of components, mole fractions; $\mathrm{V}_{\mathrm{o}}$ - volume of reaction space, $\mathrm{L} ; \omega_{\mathrm{j}}=\mathrm{W}_{\mathrm{j}} / \mathrm{C}_{\mathrm{o}}-$ adjucted reaction rates, $\mathrm{h}^{-1} ; \mathrm{j}$ - number of stages of chemical transformation; $\mathrm{i}$ - number of components.

The right-hand sides of the system of nonlinear differential equations have the following form:

$$
\begin{gathered}
\mathrm{F}_{1}=-\omega_{1}-\omega_{3} ; \mathrm{F}_{2}=-\omega_{1} ; \mathrm{F}_{3}=\omega_{1}-\omega_{2} ; \mathrm{F}_{4}=\omega_{1} ; \mathrm{F}_{5}=\omega_{2}-\omega_{3} ; \mathrm{F}_{6}=\omega_{2}-\omega_{4} ; \mathrm{F}_{7}=\omega_{1} ; \mathrm{F}_{8}=\omega_{3}-\omega_{4} ; \mathrm{F}_{9}= \\
\omega_{4} ; \mathrm{F}_{\mathrm{n}}=\omega_{2}-\omega_{4} .
\end{gathered}
$$

To solve a system of ordinary nonlinear differential equations with initial conditions at $\mathrm{t}=0$ $X_{i}=X_{i}^{o}, \bar{N}=1$ the modified fifth-order Kutta-Merson method was chosen [17].

Algorithm for solving a system of differential equations $\frac{\mathrm{dx}}{\mathrm{dt}}=\mathrm{f}(\mathrm{x})$ requires a fivefold calculation of the right-hand sides $\mathrm{f}(\mathrm{x})$ :

$$
\begin{aligned}
& \mathrm{F}_{1}=\mathrm{f}\left(\mathrm{x}_{\mathrm{k}}\right) \cdot \mathrm{h}, \\
& \mathrm{F}_{2}=\mathrm{f}\left(\mathrm{x}_{\mathrm{k}}+\mathrm{F}_{1} / 3\right) \cdot \mathrm{h}, \\
& \mathrm{F}_{3}=\mathrm{f}\left(\mathrm{x}_{\mathrm{k}}+\left(\mathrm{F}_{1}+\mathrm{F}_{2}\right) / 6\right) \cdot \mathrm{h}, \\
& \mathrm{F}_{4}=\mathrm{f}\left(\mathrm{x}_{\mathrm{k}}+\left(\mathrm{F}_{1}+3 \cdot \mathrm{F}_{2}\right) / 8\right) \cdot \mathrm{h} \\
& \mathrm{x}_{\mathrm{k}+1}=\mathrm{x}_{\mathrm{k}}+\left(\mathrm{F}_{1}-3 \cdot \mathrm{F}_{2}+4 \cdot \mathrm{F}_{4}\right) / 2 \\
& \mathrm{~F}_{5}=\mathrm{f}\left(\mathrm{x}_{\mathrm{k}+1}\right) \cdot \mathrm{h} \\
& \mathrm{x}^{*}{ }_{\mathrm{k}+1}=\mathrm{x}_{\mathrm{k}}+\left(\mathrm{F}_{1}+4 \mathrm{~F}_{4}+\mathrm{F}_{5}\right)
\end{aligned}
$$


where $\mathrm{h}$ - the step of integration over the space or time coordinate, $\mathrm{x}_{\mathrm{k}}$ - values of variables at the beginning of the integration interval. At the end of the integration interval, two solutions are obtained: $\mathrm{x}_{\mathrm{k}+1}$ - by the Runge-Kutta method with accuracy $\mathrm{O}\left(\mathrm{h}^{4}\right)$ and $\mathrm{x}_{\mathrm{k}+1}{ }-$ by the Kutta-Merson method with accuracy $\mathrm{O}\left(\mathrm{h}^{5}\right)$.

Based on the developed information-analytical system, the stage rate constants and activation energies are found. The values are given in Table 1.

Table 1. Kinetic parameters for the synthesis of benzylidene benzylamine at temperature of $23^{\circ} \mathrm{C}$.

\begin{tabular}{ccc}
\hline \multicolumn{2}{l}{ Kinetic constants, $\mathrm{h}^{-1}$} & $\begin{array}{c}\text { Activation energy, } \\
\mathrm{kcal} / \mathrm{mol}\end{array}$ \\
\hline $\mathrm{k}_{1}$ & $1.5 \times 10^{-2}$ & 10.6 \\
$\mathrm{k}_{2}$ & 4.7 & 7.7 \\
$\mathrm{k}_{3}$ & 13.4 & 1.6 \\
$\mathrm{k}_{4}$ & 0.6 & 0.4 \\
\hline
\end{tabular}

For this reaction, the adjusted and true constants are related by the following equations: $\mathrm{K}_{\mathrm{i}}=\mathrm{k}_{\mathrm{i}} \cdot \mathrm{C}_{\mathrm{o}}$ (i=1, 2, 3, 4), $\mathrm{k}_{\mathrm{i}}\left(\mathrm{L} \times \mathrm{mol}^{-1} \times \mathrm{h}^{-1}\right) ; \mathrm{k}_{5}=\mathrm{K}_{5}\left(\mathrm{~h}^{-1}\right)$.

Table 1 shows the constants at reference temperature $T_{\text {ref }}=23^{\circ} \mathrm{C}$ [73]. Recalculation of constants for any temperature is performed based on the selected reference temperature by expressions:

$$
K_{i}(T)=K_{i}\left(T_{r e f}\right) \cdot \exp \left[\frac{E_{i}}{R T_{r e f}}\left(1-\frac{T_{r e f}}{T}\right)\right] ; \quad K_{i}\left(T_{r e f}\right)=K_{i}^{o} \cdot \exp \left(-\frac{E_{i}}{R T_{r e f}}\right)
$$

To verify the adequacy of the constructed kinetic model, the calculated and experimental data are compared (Fig. 3, Fig. 4).

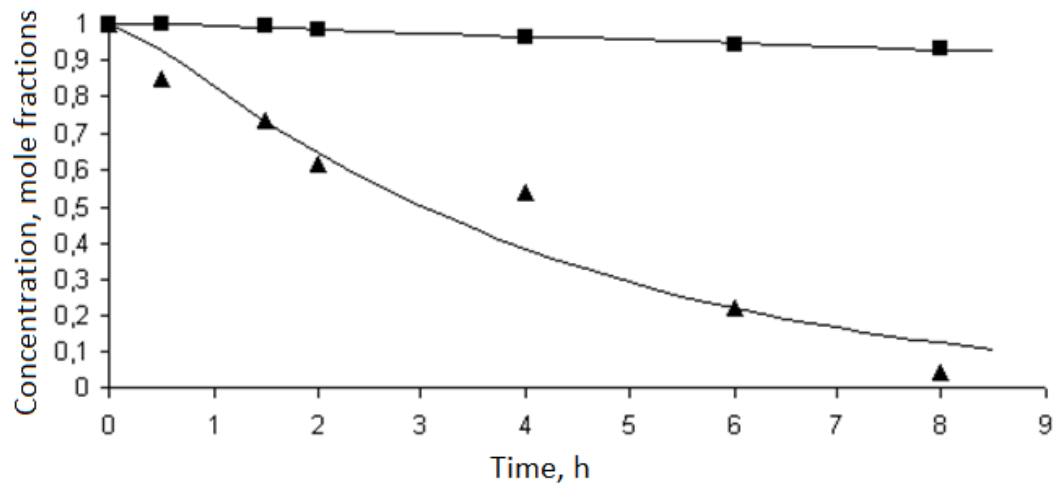

Figure 3. Calculated and experimental data on benzylamine consumption at temperatures: 1 (匹) $23^{\circ} \mathrm{C} ; 2(\boldsymbol{\Delta})-85^{\circ} \mathrm{C}$.

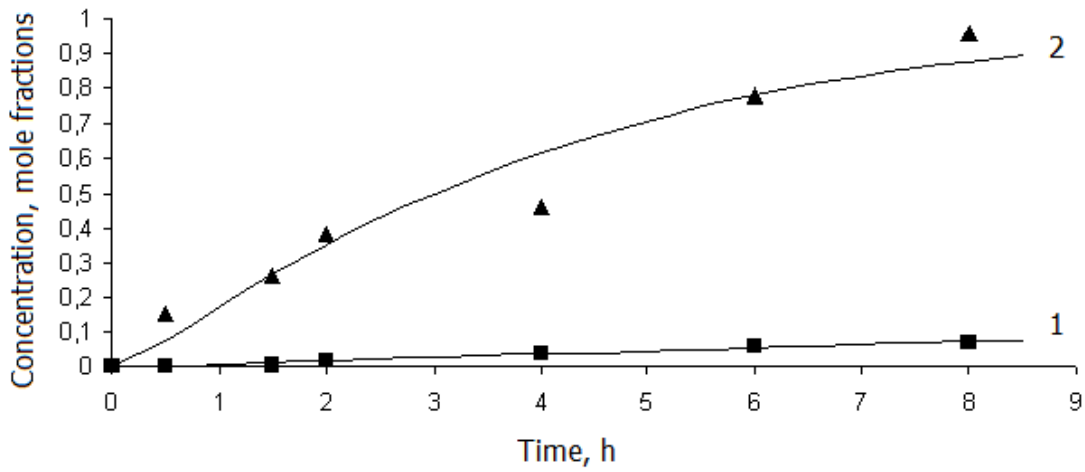

Figure 4. Calculated and experimental data on the formation of benzylidene benzylamine at temperatures: $1(\mathbf{\square})-23^{\circ} \mathrm{C} ; 2(\boldsymbol{\Delta})-85^{\circ} \mathrm{C}$. 
The developed kinetic model adequately describes the experimental observations. The divergence between the calculated data and the experimental changes in concentrations over time does not exceed the error in the quantitative analysis.

\section{Optimal reaction conditions}

Based on the developed kinetic model for the synthesis of benzylidene benzylamine, computational experiments were made. The molar ratio of the initial substances: benzylamine $\left(\mathrm{X}_{1}\right)$ and carbon tetrachloride $\left(\mathrm{X}_{2}\right)$ was chosen as the optimization criterion. The results of computational experiments on change in yield of the target product depending on the ratio $\mathrm{X}_{1}: \mathrm{X}_{2}$ at two temperatures are given in Table 2 and Table 3.

Table 2. Dependence of the target product yield on the initial substances molar ratio at $23^{\circ} \mathrm{C}$.

\begin{tabular}{ccc}
\hline $\begin{array}{c}\text { Benzylamine }\left(\mathrm{X}_{1}\right), \\
\text { molar fraction }\end{array}$ & $\begin{array}{c}\text { Carbon tetrachloride }\left(\mathrm{X}_{2}\right), \\
\text { molar fraction }\end{array}$ & $\begin{array}{c}\text { Benzylidene benzylamine yield } \\
\left(\mathrm{X}_{7}\right), \% \text { mol. }\end{array}$ \\
\hline 0.45 & 0.55 & 6.3 \\
0.40 & 0.60 & 6.9 \\
0.37 & 0.63 & 7.2 \\
0.35 & 0.65 & 7.4 \\
0.30 & 0.70 & 8.0 \\
0.25 & 0.75 & 8.5 \\
$\mathbf{0 . 1 0}$ & $\mathbf{0 . 9 0}$ & $\mathbf{9 . 7}$ \\
0.05 & 0.95 & 6.3 \\
\hline
\end{tabular}

Table 3. Dependence of the target product yield on the initial substances molar ratio at $85^{\circ} \mathrm{C}$.

\begin{tabular}{ccc}
\hline $\begin{array}{c}\text { Benzylamine }\left(\mathrm{X}_{1}\right), \\
\text { molar fraction }\end{array}$ & $\begin{array}{c}\text { Carbon tetrachloride }\left(\mathrm{X}_{2}\right), \\
\text { molar fraction }\end{array}$ & $\begin{array}{c}\text { Benzylidene benzylamine yield } \\
\left(\mathrm{X}_{7}\right), \% \text { mol. }\end{array}$ \\
\hline 0.45 & 0.55 & 80.6 \\
0.40 & 0.60 & 85.5 \\
0.37 & 0.63 & 87.9 \\
0.35 & 0.65 & 89.0 \\
0.30 & 0.70 & 92.3 \\
0.25 & 0.75 & 94.5 \\
$\mathbf{0 . 1 0}$ & $\mathbf{0 . 9 0}$ & $\mathbf{9 7 . 6}$ \\
0.05 & 0.95 & 97.1 \\
\hline
\end{tabular}

It was found that to reach the maximum product yield, the optimal molar ratio of initial substances is $\mathrm{X}_{1}: \mathrm{X}_{2}=1: 9$.

\section{Conclusions}

The information-analytical system for modeling chemical technology processes has been developed. The parallel genetic algorithm for solving inverse kinetic problems is implemented. On the basis of information-analytical system the kinetic model for the synthesis of benzylidene benzylamine has been built. The adequacy of the built kinetic model has been established. In accordance with developed model the optimal molar ratio of the initial substances has been found as benzylamine: carbon tetrachloride $=1: 9$.

\section{References}

[1] Akhmetov I V and Gubaydullin I M 2016 Analysis of methods for solving inverse problems of chemical kinetics with the use of parallel computing CEUR Workshop Proceedings $1576402-$ 410

[2] Akhmetov I V and Gubaydullin I M 2017 Parallel calculations in the construction of the kinetic model of benzylidene benzylamine synthesis CEUR Workshop Proceedings 1902 1-4 
[3] Akhmetov I V, Bobrenova YU O, Gubaydullin I M and Novichkova A V 2013 Mathematical modeling of complex chemical reactions in the presence of metal complex catalysts on the basis of multi-cycle computing systems Control Systems and Information Technology 2.1 111-115

[4] Akhmetov I V and Gubaydullin I M 2012 Development of kinetic models using parallel computations on multi-core systems Bulletin of Omsk University 2 172-174

[5] Voevodin V V and Voevodin Vl V 2002 Parallel computing (SPb: BHV-Petersburg) p 608

[6] Sadovnichy V A, Savin G I and Voevodin Vl V 2009 Supercomputer technologies in science, education and industry (Moscow: MSU Publishing House) p 232

[7] Holland J 1975 Adaptation in natural and artificial systems (Ann Arbor: University of Michigan Press) p 96

[8] Nikitin A V and Nikitina L I 2002 Evolutionary model for optimizing modular associative memory for data flow machines based on the genetic algorithm Programming 6 31-42

[9] Chernyshev O and Borisov A 2007 Comparative analysis of solving optimization problems by genetic and gradient methods Transport and Telecommunication 8 40-52

[10] Singn G and Zimmer H J 1979 Org. Chem. 44417

[11] Khusnutdinov R I, Bayguzina A R and Aminov R I Synthesis of N-benzylamine benzilidenbenzilamina under the action of iron catalysts in CCl4 Russian Journal of Organic Chemistry 48 1063-1065

[12] Kauffmann T, Habersaat K and Koppelmann E 1977 Chem. Ber. 110638

[13] Burdzhiev N T and Stanoeva E R 2006 Tetrahedron 62 8318-8326

[14] Mazitov A A, Osipova A G, Akhmetov I V and Gubaydullin I M 2016 Solution of the inverse problem of chemical kinetics using the example of the benzylidene benzylamine synthesis reaction Journal of the Middle Volga Mathematical Society 18 145-152

[15] Akhmetov I V, Gubaydullin I M, Koledina K F and Safin R R 2015 Mathematical modeling and optimization of reactions of synthesis of aromatic compounds Electrical and Information Facilities and Systems 2 53-58

[16] Khusnutdinov R I, Baiguzina A R, Mukminov R R, Akhmetov I V, Gubaidullin I M, Spivak S I and Dzhemilev U M 2010 New synthesis of pyrrole-2-carboxylic and pyrrole-2,5-dicarboxylic acid esters in the presence of iron-containing catalysts Russian Journal of Organic Chemistry $\mathbf{4 6}$ 1053-1059

[17] Polak L S, Goldenberg M Ya and Levitskiy A A 1984 Computational methods in chemical kinetics (Moscow: Nauka) p 280

\section{Acknowledgments}

The reported study was funded by RFBR according to the research projects № 18-07-00341. 